\section{PERSISTENT OMPHALOMESENTERIC DUCT WITH ACCESSORY PANCREAS}

\section{W. W. ROBLEE, M.D. \\ RIVERSIDE, CAT.}

Patient.-T. P., male, aged $21 / 2$ years, was brought to me January 6, 1908, the mother stating that the baby's umbilicus was sore and constantly moistened by a watery discharge. The birth had been a normal one, the cord came off within a week, and the navel was apparently normal until at the age of 20 months, the mother noticed a drop of blood coming from it.

Examination.-Some very small granulations appeared to r.e present at this time, but no tumor growth, and from that time on the navel remained red and moist.

History.-The gre $\cdots$ ulations were cauterized several times with silver nitrate, and in December, 1907, shortly before they came to California it was curetted by their physician, Dr. Watkins, in Washington. After they came to me, on two different occasions I touched what appeared to be two small red granulations, with chromic acid, but the discharge continued. In March, 1908, the child was attacked by an acute infection, probably influenza. He was seriously ill, and then before he fully recovered an attack of pertussis developed. During this time, about six weeks, the mother paid but little attention to tre navel, and on her return from a stay at the seashore she brought the child to my office. On inspection I found that since seeing the patient about a month previous, a small tumor mass had developed outside of, but connected by a pedicle to the umbilicus. This was one-half inch in diameter, round, red in color and very firm in consistency.

Treatment.-After excluding hernia in diagnosis I recom. mended its excision. This I did under chloroform anesthesia, and followed the excision by a thorough cauterization of its base by the electrocautery.

Result.-At this date, eight months after the performance of the operation, it has healed completely and no more moisture cccurs at the umbilicus. Whether the result will be permanent or not, I am unable to say, but I judge from the histologic findings that there will be no more trouble.

Examination of Tumors.-A vertical section through the tumor mass shows the following condition: The tumor is solid, the outer covering is composed of a layer of intestinal glands. Below this is a layer of connective tissue, then comes the central portion of the tumor, which is composed of typical pancreatic tissue, lobes, lobules, acini and characteristic islands of Langerhans. No excretory duct can be found; but one was undoubtedly present, and through it the moisture came which caused so much annoyance. Forming the base of the tumor there is another layer of connective tissue and some unstriped muscle fibres.

The explanation of the histologic findings has been difficult to arrive at, and I have been unable to find any case reports showing a like condition.

The layer of intestinal mucous membrane evidently is due to a persistence of the omphalomesenteric duct; the pancreatic tissue is a so-called accessory pancreas, which evidently became displaced in early embryologic life. I find no records of an accessory pancreas having increased in size so rapidly as did this one; in fact, the largest gland $I$ find a record of, reported by Thorel, is said to be the size of a two-mark piece. The usual size is from 1 to $2 \mathrm{~cm}$. in diameter. The age of the child speaks against carcinoma.

Warthin, Bize and Ellis all report cases of accessory pancreas in which malionancy appears to be established, and all lav stress on the possibility of such an occurrence. In this case the growth can perhaps be otherwise explained. The pancreatic nodule probably was situated under the umbilicus, and it was forced out by the paroxysms of coughing during the attack of whooping cough from which the child suffered.

I report this case because of its unusual features, in order that it may be of record; only about seventy cases of accessory pancreas have been reported up to date and none in connection with a persistent omphalomesenteric duct.

\section{A NEW DOUCHE PAN TO BE USED FOR IRRI. GATIONS AFTER SUPRAPUBIC CYSTOSTOMY \\ GEORGE WALKER, M.D. \\ Associate in Surgery, Johns Hopkins University BALTIMOBE}

The illustration shows a douche pan which facilitates irrigation of the bladder after suprapubic section. It is an every-day experience that as the fluid comes out of the wound it runs in all directions and wets patient, bed and clothing. This basin has two lateral wings, which catch the fluid as it runs down over the sides of the patient, the remainder being caught by the midile portion. The part on which the back rests is separat d from the posterior rim, so that any fluid which may run to it from around the patient's body will pass into the pan.

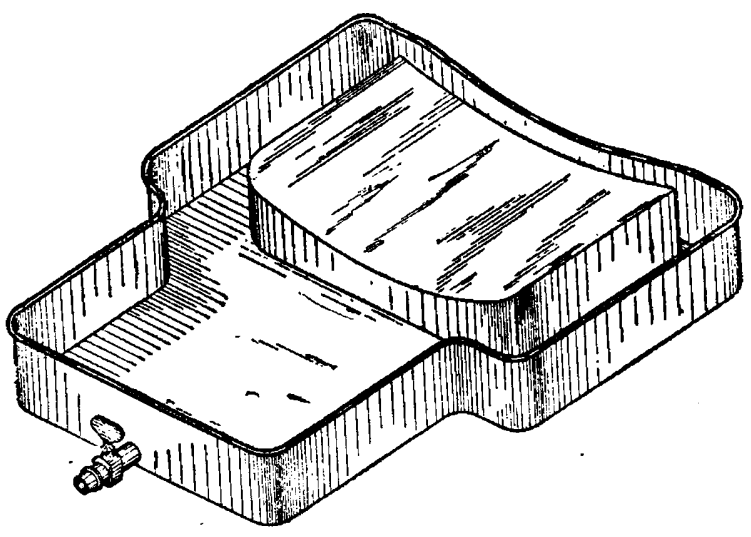

This basin has some decided advantages over the rubber pad: First, the patient does not lie in the fluid while he is being irrigated; second, it is more easily adjusted and can be removed more readily; third, it is made out of agateware or tin and is less expensive and more durable.

A somewhat extended use of this pan in my own practice has shown it to have a very definite value.

\section{SPLENIC ANEMIA IN A FIVE-YEAR-OLD BOY VAN BUREN KNOTT, M.D. SIOUX CITY, IOWA}

As the literature on splenic anemia or Banti's disease during the past five years has been both voluminous and contradictory, I shall make no effort to burden it still further with conjectures or with unverified opinions. It is my desire to place on record a case occurring in a child of 5 years, which is, so far as the literature at my command reveals. the earliest age at which the condition has been noticed.

History.-The patient, G. C., aged 5, male, was of American parentage and of negative family history. He began to walk when fourteen months oid. Four months later he became unable to walk for some unknown reason, and at the same time developed squint in both eyes, recovering completely from both difficulties in six weeks. The following year he contracted measles and whooping cough, but recovered completely with no. sequelæ.

Present Illness.-About June 1, 1908, the child began having attacks. of severe abdominal pain, which usually appeared at 
night. These attacks came on nearly every night, were invariably accompanied by vomiting and would persist for a time, varying from ten minutes to several hours. A physician who was called at this time noticed an enlargement of the patient's spleen. His mother nnticed a steady and progressive loss in weight and strength.

Physical Examination.-The child presented an extreme degree of anemia, was poorly nourished and complained of feeling tired. The spleen was found to be very much enlarged and tender to the touch. All other organs were normal. The child was unusually bright and intelligent.

Blood Examination.-Nov. 12, 1908: Hemoglobin, 32 per cent.; reds, $1,762,400$; whites, 5,890 ; neutrophiles, 78 per cent.; large lymphocytes, 4 per cent.; small lymphocytes, 17 per cent.; myelocytes, 1 per cent.

On these findings a diagnosis of splenic anemia was made and splenectomy performed November 14.

Blood Examination.--November 19: Hemoglobin, 60 per cent.; reds, 2,336,000; whites, 4,560; neutrophiles, 70 per cent.; large lymphocytes, 6 per cent.; small lymphocytes, 19 per cent; myelocytes, 3 per cent.

November 24: Hemoglobin, 70 per cent.; reds, 3,760,000; whites, 3,800 ; neutrophiles, 63 per cent.; large lymphocytes, 70 per cent.; small lymphocytes, 28 per cent.; myelocytes, 2 per cent.

December 3: Hemoglobin, 82 per cent.; reds, 4,240,300; whites, 4,250; neutrophiles, 62 per cent.; large lymphocytes, 8 per cent.; small Iymphocytes, 28 per cent.; myelocytes, 1 per cent.

As may be gathered from the above-recorded blood counts, the boy's improvement following the operation was most rapid and gratifying. He rapidly regained his strength, his appetite became ravenous and on the fourteenth day he was up playing around the hospital. It was thought advisable to keep him under observation a few days longer and he was not permitted to leave until December 4, twenty days after the operation.

Rarely have I seen a patient improve so rapidly as did this boy, and while it is much too early to consider this improvement as permanent, the prospects are most gratifying.

The points to which I desire to call particular attention are the following:

1. The tender age of the patient.

2. The steady and progressive nature of the illness and the disability occasioned by it.

3. The rapid convalescence and marked improvement both in appearance and in conduct after the splenectomy.

\section{PATHOLOGIC REPORT BY DR. E. W. MEIS.}

The spleen was $17.1 \mathrm{~cm}$. in length, $9 \mathrm{~cm}$. in width and 4 $\mathrm{cm}$. thick; weight $500 \mathrm{gm}$; purplish in appearance and had not the triangular basal surface, but was long, resembling the pancreas in outline. On the cut surface the pulp manifested unusual pallor. Microscopic examination showed striking increase of connective tissue throughout the entire organ. This tissue extended deep into the pulp and enclosed large numbers of white cells. The connective tissue around the vessels of the spleen was uniformly increased. No other departures from the nornal were noted.

\section{Therapeutics}

\section{GONORRH $\overline{\text { EA IN THE MALE }}$}

The treatment of this disease has been recently presented in this department, but it is of such importance, and Dr. Max Hühner, New York, has recently presented (New York Medical Journal, Jan. 23, Jan. 30 , and Feb. 6, 1909) so many valuable suggestions and urged so strongly the irrigation treatment, that we feel justified in again discussing the subject.

Hühner's discussion of the prophylaxis of this disease is most opportune and sensible. He shows beyond ques- tion that the consensus of the best opinion is that sexual intercourse is not necessary for the health of the individual. It is illogical to consider the sexual glands as allied to the other glands of the body, and, therefore, their specific activities, except that of their internal secretions, is physiologically intermittent, and prolonged or continued inactivity of their specific functions does not militate against their subsequent ability to perform their normal functions at any time during life. This declaration of what seems to be a fact shows that there is no necssity for illicit intercourse. Consequently, there is no necessity for acquiring gonorrhea.

There is no physical or microscopic examination that will positively determine that gonococci are not present in the glands or tissues adjacent to the vagina. Consoquently, even if repeated examinations of vaginal discharges or secretions discovered no gonococci, the inability to infect could still not be guaranteed.

Hïhner sums up his treatment of acute gonorrhea in the male as follows: If the patient is seen within thirty-six hours of the beginning of the discharge he tries to abort the disease by the administration of three injections of a 10 per cent. solution of protargol, at intervals of twelve hours, the first two injections to be held fifteen minutes, and the last one five During this period he would administer an alkaline mixture so long as there was pain on urination, and this pain is always more severe in a first gonorrhea than in subsequent attacks. He suggests the use of Professor Taylor's alkaline mixture as follows:
R.
Potassii bicarbonatis
gm. or s.c.
Tincturæ hyoscyami $\ldots \ldots \ldots \ldots \ldots \ldots$ 15 or fl.5ss
Aquæ, ad $\ldots \ldots \ldots \ldots \ldots \ldots \ldots \ldots \ldots 250 \ldots \ldots \ldots \ldots$ ad, fl.5viii
M. et Sig.: A tablespoonful, in half a glass of water, every three or four hours.

If there is any local swelling he uses both hot and cold applications. He does not say which he prefers. The hot sitz bath seems to be the best treatment.

After using the above injection as directed, Hühner then advises a 0.5 per cent. solution of zinc sulphate as an injection, as:

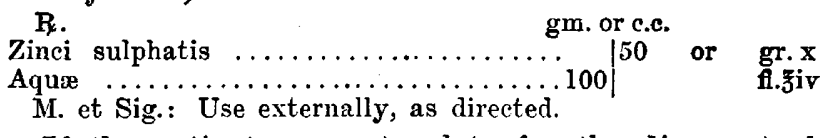

If the patient comes too late for the disease to be aborted, or if the abortive treatment is unsuccessful, he would begin deep urethral irrigations with potassium permanganate, 1 to 5,000, every day for the first two or three days, the solution being passed only with sufficient pressure to reach the deep constrictor muscle. After these two or three days he then would use sufficient pressure to pass the fluid into the bladder. Always before allowing the fluid to pass into the bladder he would wash out the anterior urethra with gentle pressure, to prevent the possibility of forcing any anterior urethral discharge into the bladder.

He defends the irrigation method on the theory that the ordinary urination and ordinary injection does not bulge out the urethra sufficiently to clean out the pus and gonococci contained in the folds of the mucous membrane, and this he believes irrigation does without injuring the mucous membrane.

On the third or fourth day he begins the vesical irrigations with the irrigator at a height of four and onehalf feet above the bladder, and gradually increases the strength of the solution to 1 to 3,000 . The irrigations are done daily until the discharge has entirely ceased, 